\title{
Factors controlling mycotoxin contamination in maize and food in the Hebei province, China
}

\author{
Zengran Liu $^{1}$ - Guangyi Zhang ${ }^{1}$ - Yi Zhang ${ }^{1}$ - Qiuxiao Jin ${ }^{1}$. \\ Jing Zhao ${ }^{1}$. Jiaojiao $\mathbf{L i}^{1}$
}

Accepted: 19 May 2016/Published online: 2 June 2016

(C) INRA and Springer-Verlag France 2016

\begin{abstract}
Mycotoxins contaminate maize and thus pose a serious economic and health risk. Despite the prevalence of mycotoxins in maize and other crops, the agricultural management system has not yet been fully implemented in China. Thereby, there is an urgent need to implement management programs to control mycotoxin contamination in maize and maize-based feed. Here, we conducted a survey on the traditional maize production and feed processing practices in the Hebei province. We analyzed the factors of fungal infection and subsequent mycotoxin contamination in maize and feed supply chain and management systems. Our results show that the stored maize samples from local feed mills were heavily contaminated with fumonisin, at $9638 \mu \mathrm{g} / \mathrm{kg}$ on the average, and deoxynivalenol, at $996.3 \mu \mathrm{g} / \mathrm{kg}$ on the average. We also found that more than $75.0 \%$ of the farmers followed good agricultural practices, whereas only $38.1 \%$ of the farmers cared for storage conditions. The main factors for mycotoxin contamination included less strict receiving and inspection criteria, inappropriate storage conditions, and poor processing practices. The critical control points were feed mill receiving, storage, and feed processing. Visual quality, moisture contents, and mycotoxin levels in maize and feed were used as monitoring parameters at critical control points. This is the first study to thoroughly explore traditional maize and feed manufacturing practices adopted by farmers.
\end{abstract}

Zengran Liu

liuzengran@163.com

1 Bioscience and Bioengineering College, Hebei University of Economics and Business, 47 Xuefu Road, Shijiazhuang 050061, People's Republic of China
Keywords Fungi $\cdot$ Mycotoxins $\cdot$ Maize $\cdot$ Maize-based feed Contamination control $\cdot$ Management practices

\section{Introduction}

Maize, the primary crop in China, are not only used as a raw material for the production of feed and industrial products (e.g., starch, maize syrup, fuel, alcohol), but also processed into various traditional foods (e.g., pancake, steamed cake, popcorn) by traditional processing techniques especially in the countryside. Nonetheless, maize is highly susceptible to toxigenic fungal infection, especially those belonging to the genera Aspergillus, Penicillium, and Fusarium, and subsequent mycotoxin contamination. Aspergillus and Fusarium species can invade maize at different production stages especially during pre- and post-harvest handling (Chulze 2010). In warm and humid conditions, maize ears are ideal parts for colonization and dominance of Aspergillus flavus and Aspergillus parasiticus (Kelley et al. 2012), resulting in aflatoxin formation. Fusarium species also cause a variety of diseases in maize, including seedling disease, stalk rots, and ear rots (Ma et al. 2013). Fusarium graminearum, Fusarium proliferatum, and Fusarium verticillioid es are the major Fusarium species in China maize (Sun et al. 2014). Fumonisins in maize and feed are produced predominantly by $F$. verticillioides and F. proliferatum in many countries including China (Voss et al. 2007). Zearalenone is primarily produced by $F$. graminearum in maize worldwide (Hueza et al. 2014).

It is shown that mycotoxins are difficult to remove or decompose from food and feed once formed (Turner et al. 2009). If the mycotoxin levels in maize and feed are not properly controlled, toxigenic fungi may cause serious economic losses, such as rejection and destruction of contaminated 
maize and risk of sickness and death to livestock and human (Calado et al. 2014). Thereby, it is urgently needed that the mycotoxin contents in food and feed are reduced to the lowest technologically and economically feasible levels (Calado et al. 2014) for promoting the sustainable development of maize industry.

Ongoing research on the control of mycotoxin contamination has not only advanced the techniques of mycotoxin detection and detoxication (Alberts et al. 2009; Heinl et al. 2010; Pereira et al. 2011; Dalié et al. 2012), but also increased the information concerning environmental factors that affect fungal colonization and subsequent mycotoxin production in oil-rich agricultural crops including maize pre- and postharvest (Paterson and Lima 2010; Wu et al. 2011; Hell and Mutegi 2011; Chang et al. 2012). It has been confirmed that mycotoxin contamination is a generally climate-dependent, plant and storage-associated problem, associated with many factors (e.g., biological factors, harvesting, storage and processing conditions, moisture content), insect damage, and preand post-harvest handling (Gnonlonfin et al. 2013). Furthermore, various best preventive practices and management systems are already in use or being developed, such as pre-harvest hazard analysis and critical control points programs for controlling aflatoxin in maize in Southeast Asia (FAO/IAEA 2001), code of practice for the prevention and reduction of mycotoxin contamination in cereals (CAC
2003). Recently, the code of practice and measures to control fumonisins in maize (discussion paper) was also released (FAO/WHO 2013). Likewise, China has issued some regulations and standards, such as the national food safety standard-maximum levels of mycotoxins in foods ( $\mathrm{MOH}$ 2011), national maize standard (SAC 2009), code of practice for the prevention, and reduction of mycotoxin contamination in cereals (SAC 2008).

Despite strengthening of safety regulations, implementation of safety management systems and conduct of considerable research on prevention of pre- and post-harvest mycotoxin contamination of agricultural crops, mycotoxin contamination of maize still occurs and remains a widely neglected issue, particularly in the countryside where monitoring and early detection of mycotoxin contamination are rarely employed (Fig. 1). Based on the evaluation of fungal infection and mycotoxin contamination in maize (Wang et al. 2010; Ma et al. 2011; Guan et al. 2011; Li et al. 2014), deoxynivalenol is the most prevalent mycotoxin detected with high incidence rate and contamination levels and some even above the minimum regulatory levels $\left(1000 \mu \mathrm{g} \mathrm{kg}^{-1}\right)$. The highest level of zearalenone was below the maximum limits set by China even though the incidence rate of ZEA was high. The levels of aflatoxin B1 varied wildly with some over the regulatory level $\left(20 \mu \mathrm{g} \mathrm{kg}^{-1}\right)$. Besides, little is known about how the farmers follow good agricultural and agro-industrial practices.
Fig. 1 Status of maize production in Hebei province. a Maize plant growing in Zhangbei county during the vegetative stage. b Maize plant growing in Wuji county during reproductive stage. c Stored maize cob infested with Aspergillus sp. or Fusarium sp. d Fungal and weevil infested maize kernels. e Maize kernels that weevil infested and sun-dried promptly. f Uninfected maize kernels


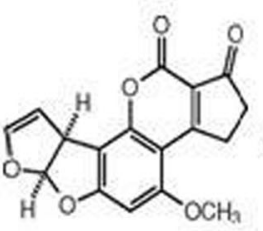

Aflatoxin B1

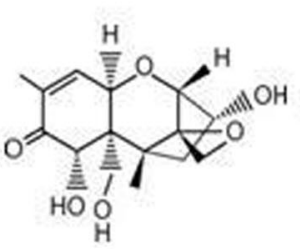

Deoxynivalenol




To help address mycotoxin challenges, mycotoxin prevention, intervention, and control management holds much promise for assuring the safety of maize and feed while preserving and enhancing the environment. Our objective in this paper was therefore to construct mycotoxin management systems in the supply chain of maize and maize-based feed, aimed at minimizing mycotoxin contamination and human and animal exposure. The approach followed is to (1) survey the current situation, (2) identify the main factors triggering mycotoxin contamination, (3) identify the critical control points, (4) set corrective action, and (5) guide post-harvest processing and storage in the supply chain of maize and maize-based feed in Hebei, a principal maize planting province in China, for improved and sustained maize production and consumption.

\section{Materials and methods}

\subsection{Field survey}

Field survey was conducted and data were collected via interview and observation from October 2013 to October 2014. A total of 160 farmers and 30 local feed mill owners were randomly selected from Wuji $\left(38^{\circ} 10^{\prime} \mathrm{N}, 114^{\circ} 37^{\prime} \mathrm{E}\right)$, Zhuolu $\left(39^{\circ} 40^{\prime} \mathrm{N}, 114^{\circ} 43^{\prime} \mathrm{E}\right)$, Cixian $\left(36^{\circ} 24^{\prime} \mathrm{N}, 113^{\circ} 42^{\prime} \mathrm{E}\right)$, belonging to Shijiazhuang, Zhangjiakou, and Handan regions, respectively, to participate in the survey. The handling practices and sanitation practices at pre- and post-harvest stages (including maize growing, harvesting, farmer storage, feed mill receiving, storage, and feed processing) were surveyed on an observation checklist. Surveyors were required to observe and record all the actions and phenomena they noticed.

The following items were included in the observation checklist. (1) Maize growing practices such as deep plow, irrigation, fertilizer and pesticide application, rotation model, and crop residue management. (2) Harvesting practices such as harvest time, harvest methods, cob drying and threshing methods, moisture content control and assay, and rotten or immature cobs sorting. (3) Farmer storage practices such as storage methods, storage facilities, storage period, insect and rodent control, moisture content control, and adopted measures. (4) Maize receiving practices of feed mills such as main factors to consider, visual examination, mycotoxin level and moisture content determination, and acceptable mycotoxin level and moisture content. (5) Storage practices of feed mills such as ventilation system, available drying facilities, maximum purchasing amount, visual inspection, moisture content and temperature monitoring, sanitary measures, pesticides and fungicides application, status of rodent attack and weevil infestation, and disposition methods of contaminated maize. (6) Handling practices and sanitary practices during feed processing such as adopted machines and facilities, handlers operation, added antifungal agent, cleaning and sanitizing, analyzed quality parameters, employee training, and technician hiring.

\subsection{Samples}

A total of 240 samples of stored maize were randomly collected in different feed production sites in three surveyed regions (92 samples from Shijiazhuang, 88 samples from Zhangjiakou, and 60 samples from Handan) of Hebei province, between October 2013 and October 2014. Maize samples were stored in warehouses, furnished no temperature control system, and adequate ventilation facilities, where the maize had been stored for more than 6 months with the starting moisture content below $15 \%$, and the common maize varieties were Zhengdan 958, Xianyu 335, Suyan 485, etc. The samples were bought to the laboratory and dried reach $14 \%$ moisture content.

\subsection{Mycotoxin extraction}

Each $1 \mathrm{~kg}$ sample was milled with a grinding instrument and thoroughly homogenized with a blender. Then a $50 \mathrm{~g}$ subsample was mixed with $250 \mathrm{ml}$ of methanol/water $\left(70: 30, v v^{-1}\right)$ extraction solution, vortexed at high speed for $3 \mathrm{~min}$, and centrifuged at $3600 \mathrm{r} \mathrm{min}^{-1}$ for $10 \mathrm{~min}$. Finally, the supernatant was collected and kept at $-20{ }^{\circ} \mathrm{C}$ for analyzing with enzyme-linked immunosorbent assay.

\subsection{Analysis of aflatoxin, deoxynivalenol, and fumonisins}

The occurrence of aflatoxin B1, deoxynivalenol, and fumonisins in the maize samples were determined by direct competitive enzyme-linked immunosorbent assay. The assay was performed according to the instructions of the test kits (Quicking Biotech Co., Ltd., SHANGHAI, CHINA: Aflatoxin B1 \# W81110; NEOGEN, SHANGHAI, CHINA: Deoxynivalenol \# 8332 and Fumonisins \# 8832). According to the manufacturers, the limits of determination are $1 \mu \mathrm{g} \mathrm{kg}^{-1}$ for aflatoxin B1, $25 \mu \mathrm{g} \mathrm{kg}^{-1}$ for deoxynivalenol, and $50 \mu \mathrm{g} \mathrm{kg}^{-1}$ for fumonisins, and the ranges of quantification of aflatoxin B1, deoxynivalenol, and fumonisins are 1$81 \mu \mathrm{g} \mathrm{kg}^{-1}, 25-250 \mu \mathrm{g} \mathrm{kg}^{-1}$, and 50-600 $\mathrm{g} \mathrm{kg}^{-1}$, respectively. To quantify the mycotoxin content in the samples, a standard curve of absorption and concentration was made using Curve Expert1.4 software. The toxin content in the sample extracts was deduced by interpolation from the standard curve.

\subsection{Statistical analysis}

Data analysis was performed by one-way analysis of variance (ANOVA) using SPSS (version 12). Descriptive statistics 
were performed with SPSS to summarize the variables of interest and determine relationships between them. $T$ test was used for average variance of the different samples with each other. $P<0.05$ was considered to be statistically significant.

\section{Results and discussion}

\subsection{Construction of typical supply chain of maize and maize-based feed}

We established the commodity flow diagram of the typical supply chain of maize and maize-based feed in Hebei province, including maize growing, harvesting, farmer storage, and maize receiving storage as well as feed processing in feed mills, using the information collected from field surveys and group discussions. Under normal circumstances, weed control, proper irrigation, fertilizer, and pesticide application, crop residue management were generally adopted. Once harvested, cobs are delivered immediately to the farmers yards and spread on concrete floors for sun drying. After 1-2 weeks, the cobs are threshed, sun dried to a safe moisture content, and then sold to the nearby feed mills or stored for a few months. In the local feed mills, the purchased maize, which is going to be stored for 1-12 months relied on their feed production requirements, is grinded and mixed with other feed ingredients, and then the finished feed is packaged and transported to the neighboring animal farms.

\subsection{Mycotoxin hazard analysis}

Neither farmers nor the subsequent feed mill owners in the surveyed regions can assure that the products they provide meet the regulatory requirements for mycotoxins. For preventing fungi from threatening the safety of maize and maize-based feed, factors triggering mycotoxin contamination were thus identified, and some pre-requisite practices were recommended (Fig. 2).

\subsubsection{Pre-harvest stage}

We surveyed the adopted management practices at pre-harvest stage. Our results showed that good agricultural practices for getting high yield, such as variety selection, planting and harvesting dates, planting distance, efficient irrigation, weed control and fertilizer as well as pesticide application were generally followed by farmers $(75.0 \%)$ under the guidance of precision agricultural service system, favoring the control of fungal infection of maize. All the farmers surveyed admitted that they conducted deep plow before planting. In addition, most of the farmers surveyed $(96.3 \%)$ removed the maize-crop residues, potential source of viable fungal spores, from the fields, and the commonly adopted disposal practice was to cut the residues into small pieces and used directly as animal feed (70.6\%). Both removal and burial of maize-crop residue can help break the chain of fungal infection or minimize the initial inoculum for subsequent crop and thus benefit fungal spore elimination and agricultural ecosystem development (Fig. 3a). According to the code of practice for the prevention and reduction of mycotoxin contamination in cereals (CAC 2003), all these agricultural practices adopted by farmers for raising maize yield can also reduce the spread and survival of fungi in the field and then mitigate the mycotoxin contamination of maize. Adversely, to raise the maize yield, farmers generally applied more than the recommended amount of pesticide, potentially posing an environmental risk.

Further, wheat-maize rotation is predominantly used year after year by farmers $(90 \%)$. Seeing that both maize and wheat have been proved to be particularly susceptible to fungal infection, the current rotation model is inappropriate, potentially increasing the fungal inoculum levels in the field and facilitating the fungal colonization of subsequent crop, and should be subsequently less used. Other crop rotation models such as soybean-maize rotation are proposed to take it over.



Fig. 2 Pre-requisite programs for mycotoxin control in the supply chain of maize and maize-based feed. Some pre-requisite practices at the appropriate stage need to be taken to prevent fungi from threatening the safety of maize and feed and assure the maize and feed meet the

regulatory limits for mycotoxins. $G A P$ good agricultural practices, $M C$ moisture content, $M L$ mycotoxin level, $M \& F$ machine and facilities, $R T$ room temperature, $E H$ environmental hygiene 
a

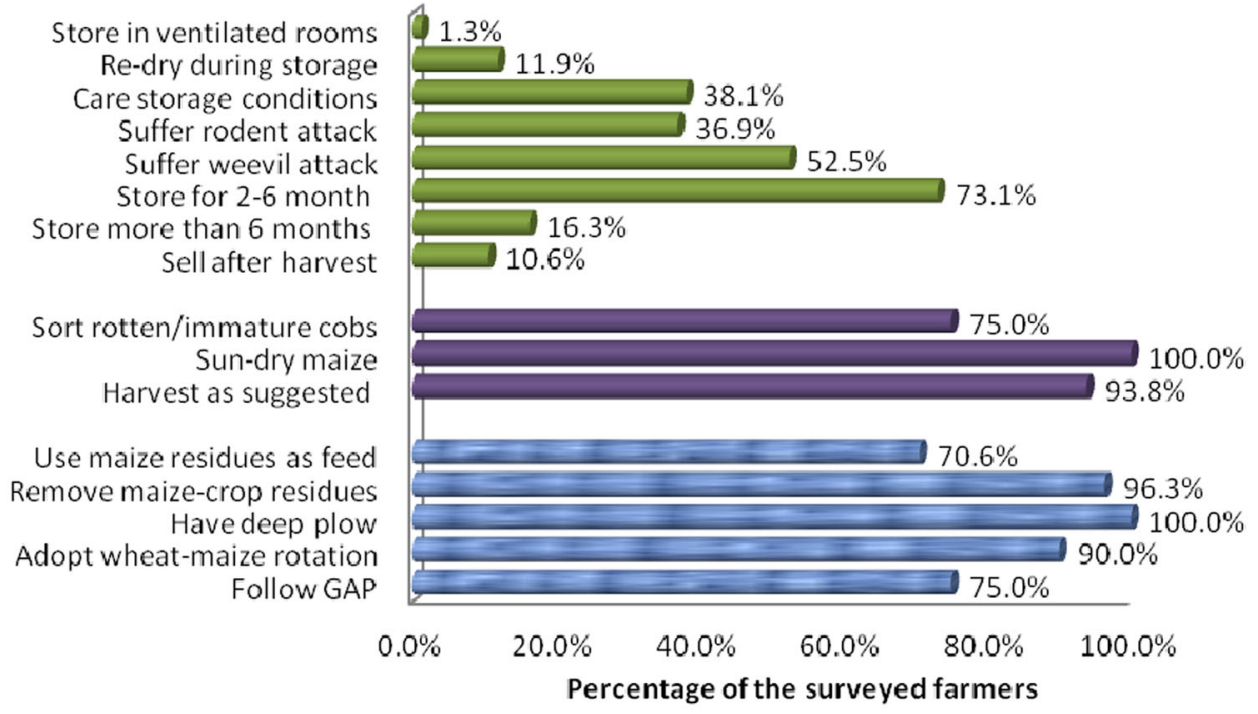

b

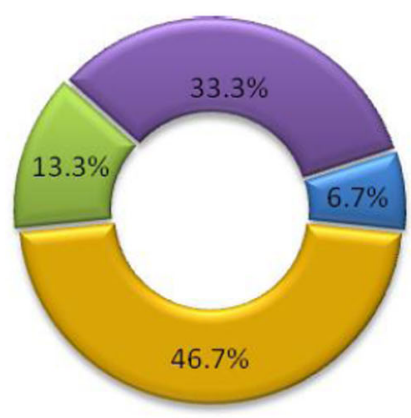

Discard contaminated maize

$\checkmark$ Sell contaminated maize for other use

$\square$ Separate contaminated maize by water flotation

Add contaminated maize in small proportion

Fig. 3 Adopted practices in maize production and maize-based feed processing. a Maize growing practices adopted by farmers. b Disposal practices of contaminated maize adopted by local feed mills. c Cleaning and sanitizing practices adopted by local feed mills. The adopted maize farming practices were more proper; the storage condition was highly varied and drying as well as storage facilities poor. For most local feed

\subsubsection{Harvest stage}

Our survey confirmed that most of the farmers surveyed $(93.8 \%)$ harvested maize under the guidance of precision agricultural service system, and maize was usually picked at 15-20\% moisture content, which is close to the suggested moisture content scope (SAC 2009), though it was not always possible. Moreover, $75.0 \%$ of the farmers surveyed sorted the rotten cobs and immature cobs prior to shelling to reduce fungal contamination of maize (Fig. 3a). However, outdoor sun drying is the only available method for reducing moisture content of maize, so that it can be very challenging to achieve
C

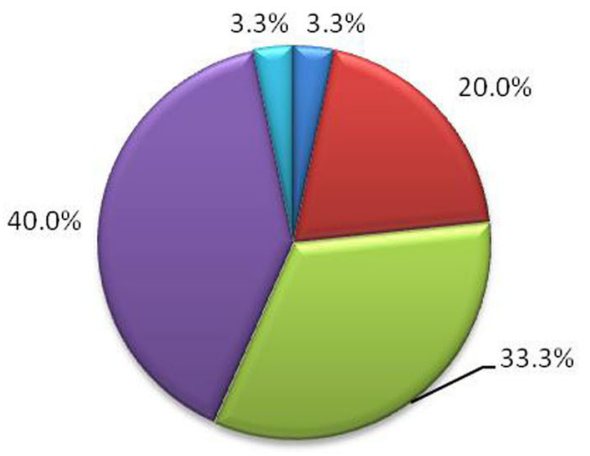

Clean/sanitize machine \& facilities \& ground regularly - Clean machine \& facilities \& ground regularily $\square$ Clean/sanitize machine \& facility \& ground occasionally $\checkmark$ Clean machine \& facilities \& ground occasionally Noclean

mills, either the current methods of disposal of infected maize or cleaning and sanitizing practices were inappropriate, highlighting the need to spread safety production practices among farmers. The data suggest that the farmers pay more attention to pre-harvest management and less attention to storage management

the safe moisture content in time, potentially favoring fungal infection, and mycotoxin contamination. It is a common practice among farmers that they estimate maize moisture content by puncturing kernels with their thumbnail or biting kernels with their teeth.

Recent research revealed that maize moisture content has a direct link to fungal growth (Hell and Mutegi 2011), and fungal infection and mycotoxin production can be controlled at safe moisture contents (Mousa et al. 2011; Astoreca et al. 2012). Subsequently, freshly harvested cobs or shelled maize with high moisture contents should be dried promptly and efficiently to safe moisture contents, say $<14 \%$, to reduce 
the risk of deterioration triggered by seed respiration and fungi attack. It is also essential that re-dry the stored maize as warm and wet weather arrives, especially if weevil damage occur.

\subsubsection{Farmer storage stage}

Our survey revealed that, in most cases, farmers just piled up bagged maize on bare floors or leaned them directly against the walls in ventilated $(1.3 \%)$ and unventilated $(98.7 \%)$ rooms, without examining the visual change of maize throughout the entire storage period. Only about $11.9 \%$ of the respondent farmers used further sun drying for maize weevil control during maize storage. With regard to storage time, some of the farmers $(10.6 \%)$ preferred to sell their maize immediately after drying; most of them $(73.1 \%)$ stored their maize for approximately 3 to 6 months, since market price was usually unfavorable at harvest time, while only $16.3 \%$ stored for longer than 6 months (Fig. 3a).

To our surprise, $36.9 \%$ of the respondent farmers stated that it was very common that their stored maize suffered from rodent attack, $52.5 \%$ of them experienced weevil infestation, the first sign of infection, in late spring and early summer, whereas only $38.1 \%$ cared storage conditions and took measures when some exceptional condition occurred (Fig. 3a). More than half of farmers told that the maize may show hot symptom and even become moldy after a half year s storage. To make things far more complex, elder farmers with less knowledge of mycotoxin contamination directly used fungal infected maize to feed livestock just to reduce maize waste.

Totally, the maize harvesting, drying, and storage practices the farmers adopted appear to be highly variable, and drying as well as storage facilities is poor; it can be very challenging for farmers to prevent the maize moldy, especially under unfavorable weather. Accordingly, we suggest that farmers adopt short-term storage and re-dried the maize if necessary. As insects and rodents can behave as vectors transporting fungal spores from one site to another, triggering the generation of heat and moisture locally, protection against rodent and insect attack should be subsequently furnished and regular exterior inspection for signs of pest activity or moldy conducted.

\subsubsection{Feed mill receiving stage}

Our survey showed that, for fear the maize with high moisture content become rotten, almost all of the feed mills (96\%) assess the quality of maize received visually and measure its moisture content, though they just set the acceptable moisture content at $15 \%$. Price was the primary factor the local feed mill owners considered when making purchase decisions. Moreover, the maize suppliers were neighboring farmers, who adopted greatly different agricultural practices, and cannot assure efficient maize quality control.
In addition to the moisture content examination, we suggest that the feed mills carry out mycotoxin levels determination to avoid the contents in maize received exceeding the maximum acceptable levels. Thorough visual inspection for color, odor, and foreign substances can also be used as an important screening step for maize fungal infection. Therefore, maize that does not meet the specifications can subsequently be identified and rejected.

\subsubsection{Feed mill storage stage}

Our survey revealed that, in the surveyed districts, it was a common practice that right after maize was harvested, the feed mill owners would purchase averagely 200 to $300 \mathrm{t}$ of maize for the feed production over the course of the next year. Once purchased, the maize was mixed with pesticides and fungicides and then transferred to the warehouses with shrunken, broken, and infected kernels as well as possible foreign particles retained. In most mills, the maize storage warehouses furnished no temperature control system, the available ventilation facilities were inadequate, and the sanitary conditions poor, though small scale producers managed to keep their stored maize in good conditions. To make things worse, maize drying facilities were not readily available in most feed mills. During warehouse storage of maize, less routine inspection was carried out, potentially resulting in large maize losses. In the spring of next year, the stored maize may get contaminated by fungi, due to large poor storage facilities and variation of environmental temperature and relative humidity.

Though the importance of fungal infection control during maize storage was generally understood, the feed mill owners were unsure how to dispose the contaminated maize. $33.3 \%$ of the owners still added the contaminated maize to feed in small proportion, $13.3 \%$ of them separated the fungal contaminated maize from the seemingly uncontaminated by water flotation, $46.7 \%$ sold the contaminated maize for other use, while only $6.7 \%$ discarded the heavily contaminated maize for fear that the consumption of feed made from heavily contaminated maize might significantly reduce animal production and immunity, although it was really very difficult for them to accept the wastage (Fig. 3b).

Mycotoxin contamination can be intensified if maize storage conditions are poorly managed. To lower the potential risk of fungal infection during maize storage, shrunken, broken, damaged, and infected kernels as well as possible foreign materials should be removed once purchased. Maize storage warehouses should be furnished with essential facilities, such as well aeration system and temperature sensors to reduce the accumulation of moisture and heat, facilitating the control of fungal infection, and thus mycotoxin production. In addition, routine inspection is performed for abnormality. 


\subsubsection{Feed processing stage}

As we have noted, feed was intermittently produced under poor sanitary conditions in most local feed mills, even though an antifungal complex was added to prevent fungal infection. In most cases, the unanalyzed finished feed was directly transferred to local animal farms for feeding animals and rarely stored for more than a few days. Additionally, our survey confirmed that only $3.3 \%$ of the feed mills regularly cleaned and sanitized machines (e.g., feed grinders and mixers, storage bins) and surrounding areas, $33.3 \%$ of them occasionally cleaned and sanitized, whereas $20.0 \%$ just regularly cleaned, $40.0 \%$ occasionally cleaned, and the remaining $(3.3 \%)$ even conducted no cleaning and sanitizing. The poor sanitary practices led to not only feedstuffs built up on the inside walls of machines and facilities, but also packages scattered all over the ground, potentially encouraging fungal growth and crosscontamination (Fig. 3c).

To prevent fungal deposits as well as cross-contamination, we recommend that not only the grinding and mixing machines, including conveying equipments, and feed storage bins be periodically cleaned and sanitized, but also feedstuff spills and litters inside and outside the workshop be cleaned up promptly. Feed mills are encouraged to employ proper measures to maintain their surrounding hygiene and litter-free. Feed quality parameters are also required to be tested regularly, if conditions allowed.

\subsubsection{Socio-economic factors}

Our survey confirmed that farmers generally cared more about how to increase maize yield and readily adopted agricultural practices in line with the advisories, whereas paid less attention to maize storage. They were actually not aware that damage-causing insects and rodents can spread fungal spores and paid less attention to the occurrence of weevils in maize. Besides, the feed mills were just prepared to adopt all possible measures to reduce feed production cost and unwilling to invest money in storage facilities so as to control fungal contamination of their stored maize. Even worse, most owners could not afford to hire a skilled technician, who can conduct processing and sanitary management so that safety and high quality of feed is assured. All these suggest that the farmer stakeholders should be trained not only on the possible adverse health effects that mycotoxins can pose to human and animals, but also on mycotoxin management practices in favor of the control of mycotoxin contamination.

\subsubsection{Mycotoxin distribution of stored maize in local feed mill warehouses}

We analyzed the aflatoxin B1, deoxynivalenol, and fumonisin levels by enzyme-linked immunosorbent assay (Table 1) to confirm the actual contamination status of the stored maize samples from local feed mill warehouses. As speculated, the results indicated that many maize samples were heavily contaminated with fumonisins and deoxynivalenol. Fumonisins were the main contaminant with average levels $1473 \mu \mathrm{g} \mathrm{kg}^{-1}$ and maximum level $9638 \mu \mathrm{g} \mathrm{kg}^{-1}$, far beyond the maximum acceptable level $\left(5000 \mu \mathrm{g} \mathrm{kg}^{-1}\right)$ set by FAO/WHO (2013), detected in a sample from Cixian, and followed by deoxynivalenol with a mean level of $996.3 \mu \mathrm{g} \mathrm{kg}^{-1}$, close to maximum acceptable level $\left(1000 \mu \mathrm{g} \mathrm{kg}^{-1}\right)$ set by China (GB 2761-2011). While average level of aflatoxin B1 was below the maximum acceptable level $\left(20 \mu \mathrm{g} \mathrm{kg}^{-1}\right)$, a maximum of $155.6 \mu \mathrm{g} \mathrm{kg}^{-1}$ was detected in a sample from Wuji.

Generally maize stored in modern warehouses equipped with sufficient ventilation has lower mycotoxin contents, while maize stored in old-fashioned warehouses with poor ventilation has higher mycotoxin contents, suggesting that all the poor storage facilities and inadequate management practices posed a major challenge to maize storage, and a prolonged period of improper and unsanitary storage conditions lead to the higher incidence rate and contamination levels.

Overall, the data on maize production and feed processing practices and mycotoxin contamination levels in feed mill stored maize mentioned above reveal that the main potential triggering factors for mycotoxin contamination in maize and feed chain are poor management practices such as less strict receiving and inspection criteria, poor processing practices, inappropriate storage practices, and imperfect cultural practices. In most cases, poor facilities, unsanitary environment, and scarce food safety knowledge pose another major challenges in preventing, controlling, and thereby lowering the incidence of mycotoxicosis. Considering that maize is the
Table 1 Mycotoxin contents in the stored maize samples from local feed mills

\begin{tabular}{llll}
\hline Mycotoxin & Incidence rate $(\%)$ & Mean of positive $\left(\mu \mathrm{gg}^{-1}\right)$ & Maximum $\left(\mu \mathrm{kg}^{-1}\right)$ \\
\hline AFB1 & 23 & 11.8 & 155.6 \\
DON & 93.3 & 996.3 & 7394 \\
FUM & 75.8 & 1473 & 9638 \\
\hline
\end{tabular}

$A F B 1$ aflatoxin B1, DON deoxynivalenol, FUM fumonisins 
main feedstuff, which accounts for more than half of the weight of feedstuffs in China, maize is a primary potential source of mycotoxins in feed and determines the feed quality to a great degree.

\subsection{Identification of critical control points}

\subsubsection{Pre-harvest and harvest stage}

At pre-harvest stage, farmers can generally carry out maize crop management as recommended, and control measures can be put in place to increase maize yields and prevent insect pest damage. As to the harvest stage, maize is picked just ahead of subsequent crop planting and sun-dried to safe moisture content, so that it is almost impossible to control the drying rate and process. Therefore, it is presently impossible to manage the two stages as critical control points for mycotoxin control in maize and feed chain.

\subsubsection{Farmer storage stage}

Due to poor storage facilities, uncontrollable ambient temperature, and relative humidity, the fungal infection of stored maize in the surveyed regions mainly rely on the weather; it is thus unpractical to designate this stage as a critical control point.

\subsubsection{Feed mill receiving stage}

To ensure mycotoxin levels in feed below the maximum acceptable levels, the first step is to reduce the mycotoxin contents in different feed ingredients. Therefore, this stage is designated as a critical control point. Feed mills should set and document specification requirements for the incoming maize, covering visual appearance, moisture contents, and mycotoxin levels.

Upon receiving the maize, representative samples should be collected and appropriate on-site quality inspection performed. Moisture content should be below $14 \%$ and mycotoxin levels including aflatoxin B1 and deoxynivalenol levels, determined by rapid test kits, below their corresponding maximum acceptable levels. If nonconforming maize batch is identified, reject it prior to unloading. For example, pink stained maize indicating Fusarium sp. and other fungi contamination should be immediately rejected.

\subsubsection{Feed mill storage stage}

Recognizing the different maize batches, mainly supplied by neighboring farmers, may have different moisture contents and contaminant levels; cross-contamination may potentially triggered when stored together in the warehouses. Insufficient moisture control and temperature rise can further worsen fungal infection of maize, particularly if the moisture problem remains undiscovered or unaddressed. This stage is subsequently a critical control point.

At this storage, the moisture contents, temperatures, smells, appearance, and insect activity should be monitored at regular intervals. Both moisture content and temperature can be used as monitoring parameters to indicate fungal growth. What is more, some visual symptoms may used as early indicators of potential hazard. For example, sour and musty odors suggest maize rotten, hair and droppings hint rodent, or insect activity in or around the warehouses. If rodent or weevil damage occurs, disposal measures should also be taken timely to avoid the spread of fungal infection.

\subsubsection{Feed processing stage}

As feed produced by local feed mills does not undergo heat treatment and detoxification, the fungi in feed still remain viable and the mycotoxin levels cannot be reduced. This stage is thus a critical control point. To ensure mycotoxin levels in feed are below the maximum acceptable levels, feed stuffs and formula are recommended to be adjusted based on the mycotoxin contents in maize and other feedstuffs, and the actual mycotoxin levels in feed should be ideally monitored on a regular basis according to national standard for feed (GB13078). Moreover, the moisture content of every batch of mixed feed should be monitored by moisture meters and dried down to critical limit (13\%) if possible. The operation of handlers is also routinely observed to ensure they are following established procedures.

\subsection{Corrective actions}

At each critical control point, if deviations from the established critical limits occur, corrective actions should be taken accordingly. At receiving stage, if any critical parameter exceeds its maximum acceptable level, the affected batch should be segregated and controlled for further disposition, and then informs supervisor for rejection of the batch and notifies the suppliers to make recall or replace in time. At storage stage, if hot spot signs are identified, run ventilation fan continuously until no further temperature rise is detected or control affected maize for further disposition, such as redry, sell for other use, or even discard. If hot spots cannot be remedied with aeration, ventilation facilities and other devices should be adjusted or replaced. At feed processing stage, if higher moisture contents or higher mycotoxin levels have been identified, control nonconforming feed for disposition, such as discard, re-dry, adjust the source of ingredients including maize or feed formulas, retrain operators, and correct unsanitary conditions. 


\subsection{Training}

Considering that most producers, handlers, processors, and marketers in the chain are farmers with less knowledge of fungal contamination and good management practices, training, hosted by local governments, should be made available to them including feed mill owners. Training topics may include the necessary skills, such as maize visual inspection techniques, feed processing techniques, feed quality control techniques as well as management programs (e.g., handling practices, storage practices, sanitation practices) designed to enhance maize and feed safety. In addition, farmers are required to pay close attention to insects and rodent control, which can spread fungal spores and promote mycotoxin production in stored maize. Importantly, they are also encouraged to package fungal contaminated maize in sealed bags before it is removed from the contaminated area to minimize the dispersion of viable fungal spores and avoid further infection. Moreover, feed mill operators should also receive training on how to perform their tasks. In particular, the personnel who will monitor critical control points should also be trained on monitoring techniques that they are responsible for and corrective procedures to be followed when nonconforming maize or feed is detected. For example, receiving personnel should be well trained on how to properly inspect maize, how to distinguish between acceptable and unacceptable maize samples, and how to determine mycotoxin levels.

Collectively, quality management system is constructed for controlling the risk of mycotoxins in maize and maize-based feed (Table 2). In the surveyed regions, three steps, which are maize receiving, maize storage, and feed processing, have been identified as critical control points. The moisture content and temperature are selected as the main monitoring parameters to reveal the real variation trend of fungal contamination.
Visual inspection is a feasible technique for farmers and local feed mills to prevent and control mycotoxin contamination.

\section{Conclusion}

To effectively cope with the mycotoxin challenge in the supply chain of maize and maize-based feed and minimize mycotoxin risk to human and animal health, mycotoxin management systems, as described in this study are constructed. The systems, in agreement with the view of sustainable agriculture, could be used as a framework for mycotoxin risk management in the maize and feed supply chain, though some preventive measures to minimize mycotoxin contamination are not able to be realistically implemented in some resource-poor countryside. The data presented could also be used as guiding tools for local regulators to attract public attention on the issue of mycotoxin contamination and propagate the importance of safety control throughout the maize and feed chain.

Given all the daunting challenge, it is hard to say that just implementing mycotoxin management systems may achieve the desired goal of contamination control. The application of such management practices is strongly linked with uncertainty. Further examination of the impact of environmental factors on the expression of the genes involved in mycotoxin production should be widely and deeply carried out, thereby facilitating the implementation of innovative strategies and efficient practices so as to reduce the mycotoxins contamination and economic and environmental losses. More profitable management system, with the potential to improve soil quality and provide greater ecosystem services, will also promote the sustainable maize production and consumption in China.

Table 2 Management plan against mycotoxin contamination in the supply chain of maize and maize-based feed

\begin{tabular}{|c|c|c|c|c|c|}
\hline $\mathrm{CCPs}$ & Triggering factors & Preventice measures & Monitoring parameters & Critical limits & Corrective actions \\
\hline $\begin{array}{l}\text { Maize } \\
\text { receiving }\end{array}$ & $\begin{array}{l}\diamond \text { Unassured maize quality; } \\
\diamond \text { High MC; } \\
\diamond \text { No mycotoxin detection. }\end{array}$ & $\begin{array}{l}\text { \& } \text { Set specification } \\
\text { \& Examine } \mathrm{MC} \text {; } \\
\text { \& Determine } \mathrm{ML} \text {. }\end{array}$ & $\begin{array}{l}\text { Gon Monitor MC; } \\
\text { Go Visual inspection; } \\
\text { Go Test MLs. }\end{array}$ & $\begin{array}{l}\triangle \mathrm{MC}<14 \% ; \\
\triangle \mathrm{No} \text { moldy evidence; } \\
\therefore \mathrm{AFB} 1<20 \mu \mathrm{gg}^{-1} .\end{array}$ & $\begin{array}{l}\text { † Reject batch with } \\
\text { unacceptable ML; } \\
\text { † Re-dry the maize. }\end{array}$ \\
\hline $\begin{array}{l}\text { Maize } \\
\text { storage }\end{array}$ & $\begin{array}{l}\diamond \text { Excessive MC; } \\
\diamond \text { No screening; } \\
\diamond \text { Inadequate warehouse } \\
\text { facilities; } \\
\diamond \text { Poor sanitary conditions }\end{array}$ & $\begin{array}{l}\text { \& Sort out unqualified; } \\
\text { \& Dry to } \mathrm{MC}<14 \% \text {; } \\
\text { \& Maintain ventilation; } \\
\text { \& Control pests; } \\
\text { \& } \text { No old/new maize mix. }\end{array}$ & $\begin{array}{l}\text { Gor Visual inspection; } \\
\text { Go Monitor MC; } \\
\text { ar Monitor temperature } \\
\text { variation }\end{array}$ & $\begin{array}{l}\triangle \mathrm{MC}<14 \% \\
\otimes \text { No visible moldy; } \\
\otimes \text { No local } \\
\text { temperature rise }\end{array}$ & $\begin{array}{l}\rightarrow \text { Run ventilation fan; } \\
\rightarrow \text { Re-dry stored maize; } \\
\rightarrow \text { Sell for other use; } \\
\rightarrow \text { Adjust ventilation facilities; } \\
\rightarrow \text { Discard. }\end{array}$ \\
\hline $\begin{array}{l}\text { Feed } \\
\text { processing }\end{array}$ & 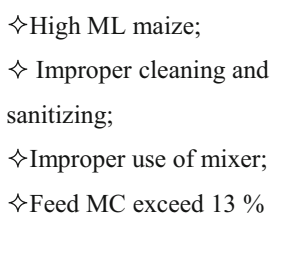 & $\begin{array}{l}\text { \& Operate mixer properly; } \\
\text { \& Clean/sanitize M\&F } \\
\text { \& Cool feed to RT; } \\
\text { \& Keep MC below } 13 \% \text {; } \\
\text { \& Maintain EH }\end{array}$ & $\begin{array}{l}\text { G Test MLs; } \\
\text { G Monitor MC; } \\
\text { G Observe operators } \\
\text { handling practices } \\
\text { Grvisual inspect } \\
\text { sanitation }\end{array}$ & $\begin{array}{l}\triangle \mathrm{AFB} 1<50 \mu \mathrm{g} \mathrm{kg}^{-1} \\
\triangle \mathrm{DON}<1 \mathrm{mg} \mathrm{kg}^{-1} \\
\otimes \mathrm{MC}<13 \%\end{array}$ & $\begin{array}{l}\rightarrow \text { Re-dry feeds; } \\
\rightarrow \text { Adjust maize source; } \\
\rightarrow \text { Adjust feed formula; } \\
\rightarrow \text { Retrain operators; } \\
\rightarrow \text { Revise sanitation procedures }\end{array}$ \\
\hline
\end{tabular}




Acknowledgments This study was supported by the Science and Technology project of Hebei Province under Grant 15225503D and by the Research Fund of Hebei University of Economics and Business under Grant 2014KYZ05.

\section{References}

Alberts JF, Gelderblom WC, Botha A, van Zyl WH (2009) Degradation of aflatoxin B (1) by fungal laccase enzymes. Int J Food Microbiol 135:47-52. doi:10.1016/j.ijfoodmicro.2009.07.022

Astoreca A, Vaamonde G, Dalcero A, Ramos AJ, Marín S (2012) Modelling the effect of temperature and water activity of Aspergillus flavus isolates from corn. Int J Food Microbiol 156: 60-67. doi:10.1016/j.ijfoodmicro.2012.03.002

Calado T, Venâncio A, Abrunhosa L (2014) Irradiation for mold and mycotoxin control: a review. Compr Rev Food Sci Food 13:1049 1061. doi:10.1111/1541-4337.12095

Chang PK, Abbas HK, Weaver MA, Ehrlich KC, Scharfenstein LL, Cotty PJ (2012) Identification of genetic defects in the atoxigenic biocontrol strain Aspergillus flavus K49 reveals the presence of a competitive recombinant group in field populations. Int J Food Microbiol 154:192-196. doi:10.1016/j.ijfoodmicro.2012.01.005

Chulze SN (2010) Strategies to reduce mycotoxin levels in maize during storage: a review. Food Addit Contam Part A Chem Anal Control Expo Risk Assess 27(5):651-657. doi:10.1080/ 19440040903573032

Codex Alimentarius Commission (CAC) (2003) Code of practice for the prevention and reduction of mycotoxin contamination in cereals, including annexes on ochratoxin $\mathrm{A}$, zearalenone, fumonisins and tricothecenes (CAC/RCP 51-2003). CAC, Rome

Dalié D, Pinson-Gadais L, Atanasova-Penichon V, Marchegay G, Barreau C, Deschamps A, Richard-Forget F (2012) Impact of Pediococcus pentosaceus strain L006 and its metabolites on fumonisin biosynthesis by Fusarium verticillioides. Food Control 23:405-411. doi:10.1016/j.foodcont.2011.08.008

FAO/IAEA Training and Reference Centre for Food and Pesticide Control (2001) Manual on the application of the HACCP system in mycotoxin prevention and control. FAO, Rome

FAO/WHO (2013) Discussion paper on fumonisins in maize and maizeproducts: code of practice and any other measures to control fumonisins in maize. Russian Federation, Moscow

Gnonlonfin GJ, Hell K, Adjovi Y, Fandohan P, Koudande DO, Mensah GA, Sanni A, Brimer L (2013) A review on aflatoxin contamination and its implications in the developing world: a sub-Saharan African perspective. Crit Rev Food Sci Nutr 53(40):349-365. doi:10.1080/ 10408398.2010.535718

Guan S, Gong M, Yin YL, Huang RL, Ruan Z, Zhou T, Xie MY (2011) Occurrence of mycotoxins in feeds and feed ingredients in China. J Food Agric Environ 9(2):163-167

Heinl S, Hartinger D, Thamhesl M, Vekiru E, Krska R, Schatzmayr G, Moll WD, Grabherr R (2010) Degradation of fumonisin B1 by the consecutive action of two bacterial enzymes. J Biotechnol 145:120 129. doi:10.1016/j.jbiotec.2009.11.004

Hell K, Mutegi C (2011) Aflatoxin control and prevention strategies in key crops of Sub-Saharan Africa. Afr J Microbiol Res 4:459-466. doi:10.5897/AJMR10.009
Hueza IM, Raspantini PCF, Raspantini LER, Latorre AO, Górniak SL (2014) Zearalenone, an estrogenic mycotoxin, is an immunotoxic compound. Toxins 6(3):1080-1095. doi:10.3390/toxins6031080

Kelley RY, Williams WP, Mylroie JE, Boykin DL, Harper JW, Windham GL, Ankala A, Shan X (2012) Identification of maize genes associated with host plant resistance or susceptibility to Aspergillus flavus infection and aflatoxin accumulation. PLoS One 7(5), e36892. doi: 10.1371/journal.pone.0036892

Li XY, Zhao LH, Fan Y, Jia YX, Sun L, Ma SS, Ji C, Ma QG, Zhang HY (2014) Occurrence of mycotoxins in feed ingredients and complete feeds obtained from the Beijing region of China. J Anim Sci Biotechnol 5:37. doi:10.1186/2049-1891-5-37

Ma JJ, Shao B, Lin XH, Yu HX, Li FQ (2011) Study on the natural occurrence of multi-mycotoxin in cereal and cereal-based product samples collected from parts of China in 2010. Chin J Food Hyg 23(6):481-488 (In Chinese with English Abstract)

Ma LJ, Geiser DM, Proctor RH, Rooney AP, O’Donnell K, Trail F, Gardiner DM, Manners JM, Kazan K (2013) Fusarium pathogenomics. Annu Rev Microbiol 67(1):399-416. doi:10.1146/ annurev-micro-092412-155650

Ministry of Health of the People's Republic of China (MOH) (2011) National food safety standards - maximum levels of mycotoxins in foods (GB 2761-2011). China Standards Press, Beijing

Mousa W, Ghazali FW, Jinap S, Ghazali HM, Radu S (2011) Modelling the effect of water activity and temperature on growth rate and aflatoxin production by two isolates of Aspergillus flavus on paddy. $\mathrm{J}$ Appl Microbiol 111:1262-1274. doi:10.1111/j.1365-2672.2011. 05134.x

Paterson RRM, Lima AN (2010) How will climate change affect mycotoxins in food? Food Res Int 43:1902-1914. doi:10.1016/j.foodres. 2009.07.010

Pereira P, Nesci A, Carlos C, Etcheverry M (2011) Field studies on the relationship between Fusarium verticillioides and Maize (Zea mays L.): effect of biocontrol agents on fungal infection and toxin content of grains at harvest. Int J Agron 2011:486914. doi:10.1155/2011/ 486914

SAC (2008) The code of practice for the prevention and reduction of mycotoxin contamination in cereals (GB/T22508-2008). China Standards Press, Beijing

Standardization Administration of China (SAC) (2009) National standard for maize (GB1353-2009). China Standards Press, Beijing

Sun J, Xie S, Liu JZ, Liu JB, Hao JJ, Deng SZ (2014) Morphological and molecular identification of Fusarium isolated from basal stalks of maize in Henan Province. Acta Phytopathol Sin 44(1):8-16 (In Chinese with English Abstract)

Turner NW, Subrahmanyam S, Piletsky SA (2009) Analytical methods for determination of mycotoxins: a review. Anal Chim Acta 632(2): 168-180. doi:10.1016/j.aca.2008.11.010

Voss KA, Smith GW, Haschek WM (2007) Fumonisins: toxicokinetics, mechanism of action and toxicity. Anim Feed Sci Technol 137:299 325. doi:10.1016/j.anifeedsci.2007.06.007

Wang W, Shao B, Zhu JH, Yu HX, Li FQ (2010) Dietary exposure assessment of some important Fusarium toxins in cereal-based products in China. J Hyg Res 39(6):709-714 (In Chinese with English Abstract)

Wu F, Bhatnagar D, Bui-Klimke T, Carbone I, Hellmich R, Munkvold G, Paul P, Payne G, Takle E (2011) Climate change impacts on mycotoxin risks in US maize. World Mycotoxin J 4:79-93. doi:10.3920/ WMJ2010.1246 